\title{
Strategic Flexibility of Enterprises
}

\author{
Joanna Radomska
}

\begin{abstract}
The paper describes the issues related to the organisation's strategic flexibility and its components. It provides a scheme presenting individual areas of the strategic management process and flexibility manifestations present therein. Research was conducted in order to verify relations between strategic advantage composed of flexible actions and the results achieved by enterprises. The existence of relations between the organisation of works on the strategy and employee participation in such actions and flexibility in allocation of roles and decision-making freedom at the implementation stage was also examined.
\end{abstract}

Index Terms - Competitive advantage, flexibility, strategy.

\section{Strategic FleXibility - A TheORETiCAl APPROACH}

Strategic flexibility is a property that allows modern organizations to prepare for (largely unpredictable) changes in their environment. According to Raynor, the concept involves an interplay of many elements, including:

- actions taken in relation to analytical studies, aimed at anticipating multiple scenarios;

- formulation of strategies for each scenario;

- acquisition of resources and skills (capabilities) needed to execute those strategies;

- implementation of the most likely strategy;

- preparing for the task of rapidly adopting an alternative strategy if needed. [1]

The classic definition by Aaker and Mascarenhas holds that flexibility represents the "ability of the organization to adapt to substantial, uncertain and fast occurring (relative to the required reaction time) environmental changes that have a meaningful impact on the organization's performance". [2] Most of the definitions found in the literature make reference to the aspect of flexibility in strategic dimension. Few, however, manage to address strategic flexibility as such, and even if they do, they lack a consistent approach to the notion at hand. For some, it represents the ability to modify strategies [3], to change the concept of development based on competences evolved through execution of prior strategies [4], or to formulate potential strategic configurations to be adopted by the company. [5] Upton defines strategically flexible companies as ones that are able to shift their operational activities into a new line of business, even if it largely departs from the previous one. [6] Therefore, literature definitions of strategic flexibility can be divided based on their main approach, namely: [7]

1) The range of possible strategic options

Manuscript received August 25, 2013; revised November 5, 2013. This work was financed with the funds of the National Science Centre as a research project no. N N115402240.

J. Radomska is with the Wrocław University of Economics, Wrocław, Poland (e-mail: joanna.radomska@ue.wroc.pl).
2) Differentiation of business activities

3) The pace of changes in competing priorities

4) The turbulence resulting from the shift into a new line of business

In addition, a complete definition of strategic flexibility should also address the internal and external dimensions, that is - dealing not only with strategic risk and environmental changes, but also the capability to employ resources proactively ad reactively. [8]

Some authors emphasize the differences between existing definitions by observing that flexibility is often used as a synonym for agility. While these two terms are interconnected, they bear different connotations from the viewpoint of company strategy. In the context of organizational development, the two terms should be interpreted separately, since they represent different levels of adaptation of the ability they refer to. Agility is typically associated with the strategic level of operation, while flexibility pertains to tactical aspects of the process. This means that developing the agility aspect requires the company to adopt a flexible approach in execution of the base processes. Therefore, the two notions should be interpreted as complementary, rather than mutually exclusive. [9] Agility requires the skill of anticipating potential opportunities in the environment, thus emphasizing the operating aspects of company functioning. [10] It should also be noted that flexibility, productivity and quality are often used as basic measures of management effectiveness. [11]

As demonstrated some of the research, companies intent on maintaining their strategic flexibility should not only keep stock of current environmental trends and changes, but also introduce and consolidate operating conditions that safeguard rapid implementation of changes, even the most radical ones. In addition, it may be useful to adopt scenarios as elements of the strategic planning process, as well as employ strategic alternatives at the stage of formulation of development concepts. [12]

The ability to cope with unpredictable environment and strategic flexibility requires ambiguity management skills, understanding of paradoxes, broadening the perspectives of current analyses and focus on activities that facilitate fast reaction to changes. [13]

It must also be noted that flexibility, despite being an essential aspect of company strategy, is by no means the only dimension. As emphasized by Evans, another important quality in this context is adaptability, meant here not only as a singular and permanent adjustment to a newly transformed environment, but also as an implied ability to make successive and temporary accommodations through interactions with environment. [14] Pathak adds to the list by postulating other elements, such as agility, versatility and resilience, which constitute the organization's flexibility and 
safeguard its long-term development. [15] Since flexibility is defined in a number of ways, the approaches to flexibility measurement are also varied. Professional literature postulates efficiency, responsiveness, versatility and robustness as potential gauges to be used for that purpose. [16]

There is also no accord among researchers as to the correlations between flexibility and productivity. While some studies show the correlation to be negative [17], others suggest a positive relation between those two notions. In addition, some authors argue that it is the correlation between flexibility and productivity that helps companies achieve long-term competitive advantage, even in highly volatile and unstable lines of business. [18] The aspect of innovativeness is also significant, since the research shows that there is a positive relation between innovativeness defined as determining new standards in a given industry and flexibility of actions and response rate, which might be considered competitive advantage. The obtained results permit the conclusion that the level of innovativeness and capability to gain the leading position in the industry increases along with flexibility growth. [19]

Strategic flexibility is undeniably linked with planning formulation and implementation. As shown in empirical research, dynamic and successful companies do take into account the effects of external factors, even if they adopt fairly routine planning processes. In such cases, planning strategies typically include the so-called flex points, i.e. elements that change depending on external circumstances. It is worth noting that those companies represent a cohesive approach to strategy formulation and selection, while their concept of development is focused on risks and hazards, which are interpreted as potential sources of competitive advantage. By contrast, companies representing a rigid approach to strategy not only disregard the effects of external factors in their planning processes, but also pursue their strategic objectives with no regard for any previously adopted plans, taking up a passive attitude and risk avoidance. Such companies are characterized by strong resistance to change and a conservative organizational culture focused on error elimination. [20]

Furthermore, as found in this some of the empirical research, strategic flexibility is correlated with the company's results, particularly in times of turbulent changes brought about by the present economic crisis. This correlation is especially important for companies operating on highly competitive markets, as opposed to markets characterized by high uncertainty of demand or technological progress, where strong market orientation at the cost of flexibility is the preferred approach. [21]

The paradox of strategic flexibility lies in the fact that strategy formulation requires careful analyses, and these are not possible, since forecasts of market development and environmental changes are burdened with high-level uncertainty. Moreover, it is almost impossible for a large company to retain its agility and responsiveness to dynamic changes in conditions of market competition. At the same time, the larger the company, the more resources can be directed to conduct multifaceted analyses and design various scenarios of environmental changes. Therefore, the key to success lies i proper balance between real flexibility and its model representation. Raynor suggests that one of the ways to cope with the paradox of strategy is to implement strategic flexibility in a proactive manner, as a set of ex ante actions. [22]

Hatch and Zweig also analyze flexibility in terms of organization size, by emphasizing the flexibility advantages of small companies, namely - the lack of highly formalized systems and processes that results in reduction of time needed for decision-making and implementation. This allows them to respond promptly to market development and adjust their competitive position. The potential for rapid change and evolution offers them a chance to gain competitive advantage and survive. However, as emphasized by the authors, with size increase, this lack of rigid and formalized rules becomes an obstacle to operational effectiveness. This risk forces companies to institutionalize some of their processes, with the effect of leveling their flexibility advantage. This is why it is important to be aware of the risks involved in company development and promptly introduce measures to compensate for the negative effects of company growth. [23]

According to Johnston, the key competence lies in transposition of current limitations in such a way as to effect support for new organizational functions, eliminate some of the burdens involved, and react to new environmental conditions. This process is unquestionably linked with multidimensionality and changes in three aspects of operation - the changing functions (flexibility), operational environment (portability) and resource load (measurability). [24]

One of the main benefits of employing the flexibility aspect is the increased resilience to risk. This leads to another paradox of strategic management - the more irreversible the investment decisions; the lesser is the margin for changing them and adjusting the strategy to current situation. This, in turn, leads to elevated risk level. However, if the company chooses to focus on flexibility of strategy and forfeits all investment decisions, it may face the situation where no strategy can be safely implemented - not even the best one. This, again, leads to elevated risk, although of a different character. It should also be noted that as a result of changes in the environment, it is not always possible to exploit temporary competition opportunities based on strategic flexibility, due to certain internal constraints. These may include technological barriers or any existing connections and arrangements with company stakeholders. [25]

To sum up, all the authors quoted above are unanimous in their evaluation of the role of strategic flexibility in strategic management process. And, despite the lack of a unified definition of the concept, professional literature emphasizes the need to take this aspect into account in the day-to-day company operation. [26]

\section{RESEARCH QUESTIONS AND METHODOLOGY}

A scheme comprising strategic management process components constituting strategic flexibility, which has been adopted as the basis for further research, is presented in Table I below. 
TABLE I: STRATEGIC FLEXIBILITY - FRAMEWORK

\begin{tabular}{|c|c|}
$\begin{array}{c}\text { Strategic } \\
\text { management } \\
\text { area }\end{array}$ & \multicolumn{1}{c|}{ Flexibility manifestations } \\
\hline $\begin{array}{c}\text { competitive } \\
\text { advantage }\end{array}$ & $\begin{array}{l}\text { temporary, short-lived, requiring modification in } \\
\text { the activity profile }\end{array}$ \\
\hline $\begin{array}{c}\text { organisation of } \\
\text { works on the } \\
\text { strategy }\end{array}$ & $\begin{array}{l}\text { the strategy is developed on a day-to-day basis, } \\
\text { works are performed irregularly, there are no } \\
\text { scheduled meetings or sessions }\end{array}$ \\
\hline $\begin{array}{c}\text { employee } \\
\text { participation }\end{array}$ & $\begin{array}{l}\text { employees are engaged at the strategy development } \\
\text { stage, they have an opportunity to decide on the } \\
\text { method of its implementation, roles are allocated in } \\
\text { a flexible manner in response to current needs }\end{array}$ \\
\hline $\begin{array}{c}\text { strategy content } \\
\text { the strategy assumes the form of an informal idea, it } \\
\text { is at times formulated only in the form of basic } \\
\text { development rules and principles }\end{array}$ \\
\hline strategy horizon & a short horizon of the devised strategy \\
\hline $\begin{array}{c}\text { domain of } \\
\text { activity }\end{array}$ & $\begin{array}{l}\text { a continuous search for new fields of activity (both } \\
\text { in terms of market and product), it is facilitated by } \\
\text { cooperation with partners from other industries }\end{array}$ \\
\hline $\begin{array}{c}\text { strategy } \\
\text { implementation }\end{array}$ & $\begin{array}{l}\text { the strategy implementation plan development and } \\
\text { its concept creation are simultaneous }\end{array}$ \\
\hline Source: own work. & \multicolumn{2}{|c|}{}
\end{tabular}

In order to verify the presented scheme, there were formulated research hypotheses for individual strategic management process areas. They are presented in the Table II below:

TABLE II: RESEARCH HYPOTHESES

\begin{tabular}{|l|l|l|}
\hline \multirow{4}{*}{} & $\begin{array}{l}\text { Competitive } \\
\text { advantage }\end{array}$ & $\begin{array}{l}\text { H1: Modification in the activity profile } \\
\text { affects revenue dynamics. }\end{array}$ \\
\cline { 2 - 3 } & $\begin{array}{l}\text { Strategy } \\
\text { content and } \\
\text { domain of } \\
\text { activity }\end{array}$ & $\begin{array}{l}\text { H2: There is a relation between an } \\
\text { informal strategy form and a continuous } \\
\text { search for new fields of activity. }\end{array}$ \\
\cline { 2 - 3 } $\begin{array}{l}\text { Flexibility } \\
\text { and } \\
\text { response } \\
\text { rate as } \\
\text { competitive } \\
\text { advantage }\end{array}$ & $\begin{array}{l}\text { Organisatio } \\
\text { n of works } \\
\text { on the } \\
\text { strategy }\end{array}$ & $\begin{array}{l}\text { H3: There is a relation between the } \\
\text { day-to-day strategy revision and } \\
\text { readiness to modify the activity profile. }\end{array}$ \\
\cline { 2 - 3 } & $\begin{array}{l}\text { H4: Regularity of works on the strategy } \\
\text { is related to flexible allocation of roles } \\
\text { during its development and } \\
\text { implementation. }\end{array}$ \\
\cline { 2 - 3 } & $\begin{array}{l}\text { Strategy } \\
\text { horizon }\end{array}$ & $\begin{array}{l}\text { H5: The longer the strategy horizon, the } \\
\text { greater the necessity to modify the } \\
\text { activity profile during its } \\
\text { implementation. }\end{array}$ \\
\cline { 2 - 3 } & $\begin{array}{l}\text { Empl The greater the level of employee } \\
\text { participatio } \\
\text { n }\end{array}$ & $\begin{array}{l}\text { engagement in the strategy development } \\
\text { process, the greater their } \\
\text { decision-making freedom in } \\
\text { implementation. }\end{array}$ \\
\hline
\end{tabular}

Source: own work.

The results presented below are a part of broader research on the evolution of the strategic management process occurring along with enterprise development. The sample size was 150 entities, which were divided according to the criterion of size. The sample included 50 small enterprises (employing up to 49 persons), 50 medium enterprises (50-249 persons) and 50 large enterprises (employing more than 250 persons). The research was conducted by means of a paper and pencil interview - the method based on collecting data in an open (overt) and standardized manner was applied in the quantitative research. The respondent group included entities whose legal form was joint-stock company, half of which (precisely 50.7\%) were quoted on the Warsaw Stock Exchange. Additionally, all companies were established after 2009 and were Polish-owned. The respondents were the enterprise management staff, with executive directors, managing directors or the management board - defined as the chairperson of the management board and members of the management board. The basis for conducting the interview was a survey questionnaire consisting of 84 questions grouped by 19 research areas. The companies that confirmed the significance of flexibility as an indispensable component of creating competitive advantage were selected for further examination. They provided an affirmative answer to the statement "Flexibility and response rate are the most important competitive advantage of our enterprise." They were 103 entities.

\section{RESULTS AND DISCUSSION}

Relations determined based on the Kendall's tau-b correlation coefficient, which is a non-parametric measure of correlations for ordinal variables, were checked in order to verify the hypotheses. Since the questions asked in the questionnaire assumed the ordinal scale, the application of this correlation can be considered justified. The results are presented in the Table III below.

TABLE III: CORRELATIONS CALCULATED By MEANS OF THE KENDALL'S

\begin{tabular}{|c|c|c|}
\hline TAU-B METHOD \\
\hline Hypothesis & Correlation & $\boldsymbol{p}$-value \\
\hline H1 & 0,097 & 0,28 \\
\hline H2 & 0,123 & 0,16 \\
\hline H3 & $-0,146$ & 0,08 \\
\hline H4 & $-0,242$ & 0,01 \\
\hline H5 & 0,025 & 0,77 \\
\hline H6 & 0,296 & 0,00 \\
\hline
\end{tabular}

Source: own work based on the results of the conducted research

As the conducted research proves, four of the formulated hypotheses are statistically irrelevant and therefore no conclusions concerning the adopted assumptions that could be generalized for the entire population can be drawn on their basis; it is only possible to refer to the examined sample.

The obtained results do not allow the acceptance of hypothesis one, which indicates the existence of a relation between flexibility defined as readiness to modify the activity profile in order to achieve competitive advantage and the achieved financial results. Hence, it is impossible to state that the revenue gained by the examined enterprises is an effect of applying the flexible development concept. It can be assumed that the success of the strategy measured with financial result does not depend on flexible approach to achieving competitive advantage and what contributes there is, above all, implementation actions and their effectiveness. The declaration of readiness to change the activity profile alone does not always involve taking relevant operational decisions, which determine the final results of strategic actions to a large extent.

The results also indicate that hypothesis two needs to be rejected as there is no relation between flexibility in the domain of activity and informal approach to strategy development. Recording the strategy in the form of basic development rules and principles or a mere idea, without determining precise and specific manners of its implementation, is not related to the readiness to seek new (market or product) fields of activity. Hence, there are no 
relations between flexibility in the area of strategy content and the form it assumes and expansiveness in achieving competitive advantage. It turns out that the lack of formalization and preparation of elaborated strategic documents does not contribute to greater flexibility of the actions taken to improve the competitive position.

Similar conclusions regard hypothesis three, which refers to the relation between flexibility in the area of strategic advantage and developing the strategy on a day-to-day basis, with the formal planning stage omitted. This is because the results of the research do not prove the existence of a relation between these two aspects. Therefore, it can be concluded that there is no relation between strategy revision, which is carried out in line with the development concept implementation stage, and the organization's readiness to adapt the profile of the pursued activity to market requirements in a flexible manner. Strategy adjustments, which are made on an ongoing basis, concern revision of the adopted assumptions or actions serving their execution rather than modification of the manner in which competitive advantage is achieved.

The results obtained from the verification of hypothesis five seem interesting - this is because it cannot be assumed that it is necessary to modify the activity profile more frequently alongside with the strategy horizon growth. This might mean that competition conditions, while enforcing the shortening of the planning horizon and development concept creation, at the same time affect the frequency of strategy revision. Hence, it can be assumed that it is a flexibility aspect, since the actions taken to this end are not planned in advance but they arise from limitations and the competitive situation on a given market. The created development concepts are characterized by a short horizon, which results from the necessity to adapt to market principles; therefore, the factors enforcing strategy modification are the market and competitors rather than time defined as the horizon of the devised development concepts.

Two hypotheses can be considered statistically relevant, namely hypothesis 4 and 6, and the obtained results indicate the existence of weak relations between the examined areas. There is a negative relation between the regularity of works on the strategy and allocation of roles when developing and implementing it, which is formed in a flexible manner as a response to the currents needs. What follows from the research is that flexibility, which is composed of ongoing strategy development, irregularity of the performed works and the lack of meetings and sessions dedicated thereto, translates into flexibility in allocation of authority, tasks and responsibility for its individual components. The more irregular the actions taken to develop the strategy are, the greater decentralization of responsibility for the decisions made occurs. Hence, it can be stated that the flexibility of conceptual works is reflected in the flexibility of their performance.

The last hypothesis examined relations in the area of employee participation and indicated the existence of an average relation between the level of employee engagement in the works on creating a development concept and their performance. The employee decision-making freedom as regards issues related to strategy implementation definitely is a manifestation of strategic flexibility. It permits taking implementation decisions in accordance with the requirements of the environment and internal limitations, and employee participation in the works at both conceptual and implementation stage proves the willingness to ensure the best possible adaptation of the developed strategies to their implementation capability.

\section{CONCLUSION AND FURTHER RESEARCH}

As was mentioned above, the conducted research was aimed at verifying the relations between individual areas of the strategic management process distinguished by the feature of flexibility. No relations between strategy flexibility and the achieved financial results or the readiness to modify the activity profile were detected. There is, however, a relation between flexibility and irregularity of the works on the strategy and the forming allocation of roles when their performance and the level of employee engagement in conceptual works and their decision-making freedom regarding the implementation of the developed strategies. The research was based on the adopted scheme, which was devised as an effect of literature review and research experience of the author. Further in-depth research is advisable in order to verify its components and identify the existing deficiencies and potential improvements. The complex subject matter of strategic flexibility was certainly not exhausted - the direction for further research was only determined. It would be worth investigating the results for groups of enterprises distinguished based on the criterion of size and checking whether flexibility is a characteristic feature of mainly small entities. What also deserves attention is issues related to the change of enterprise practices along with their growth - whether strategic flexibility occurs together with the organization's maturing process or whether it is a feature that gradually disappears with its development.

\section{REFERENCES}

[1] M. Raynor, "Strategic flexibility," A Deloitte Research Monograph, pp. 1 .

[2] D. Aaker and B. Mascarenhas, "The need for strategic flexibility," Journal of Business Strategy, vol. 5, no. 2, pp. 74, 1984.

[3] E. Frazelle, "Flexibility: A strategic response in changing times," Industrial Engineering, no. 3, pp. 17-20, 1986.

[4] R. Hayes and G. Pisano, "Beyond world-class: The new manufacturing strategy," Harvard Business Review, pp. 77-86, 1994.

[5] K. Clark, "Competing through manufacturing and the new manufacturing paradigm: Is manufacturing strategy passé," Production and Operations Management, vol. 5, no. 1, pp. 42-58, 1996.

[6] D. Upton, "The management of manufacturing flexibility," California Management Review, pp. 72-89, 1994.

[7] A. Toni and S. Tonchia, "Definitions between operational and strategic flexibilities," The international Journal of Management Science, no. 33 , pp. 538, 2005.

[8] N. Roberts and G. Stockport, "Defining Strategic flexibility," Global Journal of Flexible Systems Management, vol. 10, no. 1, pp. 29.

[9] J. Baker, "Agility and flexibility: What'S the difference," Cranfield School of Management, no. 5, pp. 6, 1996.

[10] E. Bernardes and M. Hanna, "A theoretical review of flexibility, agility and responsiveness in the operations management literature, toward conceptual definition of customer responsiveness," International Journal of Operations and Production Management, vol. 29, no. 1, pp. 47, 2009.

[11] A. M. Sanchez, J. M. V. Jimenez, M. P. Perez, and P. D. L. Carnicer, "Innovation and labor flexibility, a Spanish study of differences across 
industries and type of innovation," International Journal of Manpower, vol. 30, no. 4, pp. 360-376, 2009.

[12] E. Widati, "Resolving the strategy paradox applying the strategic flexibility: A case study of PT BNI life insurance," International Research Journal of Business Studies, vol. 5, no. 2, pp. 160-161.

[13] A. Gray and N. Olynk, "Making decisions that provide strategic flexibility," Agri Marketing, pp. 21, June 2011.

[14] J. Evans, "Strategic flexibility for technology manoeuvres: a conceptual framework," Journal of Management Studies, vol. 28, no. 1, pp. 73, 1991

[15] R. C. Pathak, "Flexibility- thinking shift of organizational excellence," Global Journal of Flexible Systems Management, vol. 6, no. 3/4, pp. 59-69, 2005.

[16] W. Golden and P. Powell, "Towards a definition of flexibility: In search of the Holy Grail," The International Journal of Management Science, no. 28, pp. 373-384, 2000.

[17] F. Suarez, M. Cusumano, and C. Fine, "An empirical study of flexibility in manufacturing systems," Sloan Management Review, no. 37, pp. 25-32, 1995.

[18] B. Dreyer and K. Grønhaug, "Uncertainity, flexibility and sustained competitive advantage," Journal of Business Research, no. 57, pp. 492, 2004.

[19] L. S. Pelc and J. Radomska, "Factors determining the process of creating and implementing a strategy based on innovation and technology," in Proc. 21st International Business Information Management Association Conference Vision 2020: Innovation, Development Sustainability, and Economic Growth, Vienna, Austria, June 2013, pp. 449-450.

[20] C. Dibrell, J. Down, and L. Bull, "Dynamic strategic planning: Achieving strategic flexibility through formailization," Journal of Business and Management, vol. 13, no. 1, pp. 31-33, 2007.
[21] R. Grewal and P. Tansuhaj, "Building Organizational capabilities for managing economic crisis: The role of market orientation and strategic flexibility," Journal of Marketing, vol. 65, pp. 76, 2001.

[22] M. Raynor, The Strategy Paradox: Why Committing to Success Leads to Failure and What to Do About It, New York: Currency Doubleday Press, 2007

[23] J. Hatch and J. Zweig, "Strategic flexibility: The key to growth," Ivey Business Journal, pp. 44, March/April, 2001.

[24] A. Johston, "Strategies for flexibility," Questa Computing, pp. 1, 2001.

[25] T. Das, "Managing strategic flexibility: Key to effective performance," Journal of General Management, vol. 20, no. 3, pp 3-11, 1995.

[26] L. S. Pelc, "Strategic management in face of new challenges," in Theory of Management 4, The Selected Problems for Development Support of Management Knowledge Base, Štefan Hittmár, Žilina Slovakia Eds 2011, pp. 56-61.

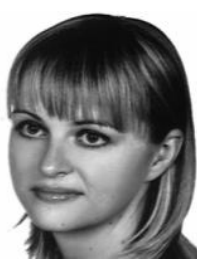

Joanna Radomska was born on December 23, 1983 in Opole, Poland. She graduated her master studies at Wroclaw University of Economics in 2007. In 2011 she graduated $\mathrm{PhD}$ studies at the same institution. Her $\mathrm{PhD}$ thesis was connected with the topic of Employee participation in strategic management process. She works as an Assistant Professor at Wroclaw University of Economics, in Strategic Management Department.

Her research interests are connected with strategy implementation and communication, participative management, change management and project management 